\title{
Rehabilitación neuropsicológica en paciente con afasia transcortical motora: estudio de caso.
}

Neuropsychological rehabilitation in patients with motor transcortical aphasia: case study.

\author{
Jesús A. Luna-Padilla ${ }^{a}$, Ángel F, Villalva-Sánchez ${ }^{b}$,Carmina Aguilar-Silvac.
}

\begin{abstract}
:
Aphasia is a disorder that is characterized by loss or deterioration of the complex processes necessary for the understanding and expression of language. The main cause of these disorders are cerebral vascular events. Rehabilitation treatments in these patients are focused on expression in processes such as verbal fluency and nomination, as well as verbal comprehension. The aim of this work was to perform a neuropsychological intervention in a patient with transcortical motor aphasia. An intervention plan of 19 sessions was carried out to improve the performance in the nomination through semantic and phonological cues, as well as sessions focused on the understanding of oral commands. The results showed improvements in the number of words nominated and a slight improvement in comprehension. It was concluded that the implemented tasks generated improvement in these processes, being the phonological aids with better effect on the semantics, as well as improvements in their activities of the patient's daily life.
\end{abstract}

Keywords:

Stroke, Transcortical aphasia, Rehabilitation, Neuropsychology, Cognition

\begin{abstract}
Resumen:
Las afasias son la pérdida o deterioro de los procesos complejos necesarios para la comprensión y expresión del lenguaje. La principal causa de estos trastornos son los eventos vasculares cerebrales (EVC) los cuales afectan el hemisferio dominante del lenguaje principalmente. Los principales tratamientos de rehabilitación en dichos pacientes son enfocados en la expresión en procesos como nominación y fluidez verbal y además de la comprensión verbal. El presente trabajo tuvo como objetivo realizar una intervención neuropsicológica en un paciente con afasia transcortical motora. Se realizó un plan de intervención de 19 sesiones para mejorar el desempeño en la nominación mediante pistas semánticas y fonológicas, así como sesiones enfocadas a la comprensión de ordenes orales. Los resultados mostraron que el paciente mostró mejorías en la cantidad de palabras nominadas y una ligera mejoría en la comprensión. Se concluyó que las tareas implementadas generaban mejoría en dichos procesos, siendo las ayudas fonológicas con mejor efecto sobre las semánticas, así como mejorías en sus actividades de la vida diaria del paciente.
\end{abstract}

\section{Palabras Clave:}

EVC, Afasia transcortical, Rehabilitación, Neuropsicología, Cognición

\section{Introducción}

La afasia es un síndrome neuropsicológico que se caracteriza por la pérdida o el deterioro de los procesos complejos necesarios para la comprensión y expresión del lenguaje, el cuál es adquirido por un daño cerebral, afectando una variedad de redes neuronales, a nivel cortical y subcortical. Algunas de sus principales manifestaciones son pérdida en la nominación de objetos, fluidez verbal, gramática, y comprensión del lenguaje oral (Bruna, Puyuelo, Junque \& Ruano, 2011).

\footnotetext{
a Universidad Nacional Autónoma México, FES Iztacala Laboratorio de neurometría email: jesus_lup@hotmail.com

b Autor de correspondencia. UNAM FES Iztacala Laboratorio de neurometría email: angel.villalva@iztacala.unam.mx

Pasante de la carrera en psicología de la Escuela Superior Actopan, Universidad Autónoma del Estado de Hidalgo, email: 
Una de las causas principales de la afasia es el ictus, clasificado dentro de los eventos cerebrales vasculares (EVC) (Lozano \& Ortuño, 2011). La prevalencia de las afasias causadas por EVC, oscila entre el 19\%-38\%, un aproximado de 4.5 de cada 1000 casos (Basso, Forbes \& Boller, 2013). Los eventos vasculares alterar la irrigación sanguínea del cerebro comprometiendo la oxigenación y la distribución de los nutrientes, lo cual puede ocasionar la muerte del tejido cerebral. Al producirse un EVC, el riego sanguíneo se interrumpe por alguno de los siguientes mecanismos (Lozano \& Ortuño, 2011):

Oclusión (Evento isquémico): el tejido muere debido a la interrupción del flujo de sangre al cerebro y puede ser por dos condiciones: 1) trombosis, el cual consiste en la progresiva estrechamiento de los vasos sanguíneos causada por la acumulación de placas en sus paredes y 2) embolia, la cual es la oclusión de un vaso sanguíneo por un émbolo de sangre, burbuja de aire, el cual viaja a lo largo del sistema arterial hasta llegar a una zona estrecha.

Hemorragia: al producirse una ruptura arterial se altera la irrigación sanguínea normal, por lo que la sangre se esparce sobre el tejido cerebral y produce un aumento en la presión intracraneal.

Estas lesiones pueden dañar distintas zonas del hemisferio izquierdo, y dependiendo de la zona dañada presentará características de cada una de las afasias, dependiendo la amplitud de la lesión, entre las regiones afectadas son: el área de Broca, área de Wernicke, surco temporal superior, áreas inferiores del lóbulo temporal y el fascículo arqueado (Bruna, Puyuelo, Junqué \& Ruano, 2011).

Ahora bien, la Afasia Transcortical Motora (ATM) se caracteriza por una fluidez alterada, comprensión relativamente conservada, presencia de parafasias fonológicas, y anomias, repetición ligeramente alterada, una lectura y escritura alterada. Las regiones lesionadas a este tipo de afasia es zonas adyacentes al área de Broca, porciones profundas del lóbulo frontal izquierdo, extendiéndose hasta áreas pre-motoras, corteza motora, y zonas anteriores del ventrículo lateral (Diéguez-Vide \& Peña-Casanova, 2012).

En la intervención neuropsicológica de ATM se han propuesto programas cuyo objetivo es mejorar la fluidez verbal y con ella las parafasias. En algunos programas para la rehabilitación del lenguaje expresivo, se ha implementado la nominación de distintos objetos con ayudas en distintas vías, sensoriales, fonológicas y táctiles; reportando mejorías en la expresión del lenguaje y en las actividades cotidianas (Galindo, Pelayo y Quintanar, 2014; Rodríguez et al., 2011). De la misma manera Chen et al. (2015), compararon dos programas de intervención, el primero consistía en la presentación de imágenes en una pantalla, donde el rehabilitador nomina en voz alta el nombre del objeto, por otro lado, a otro grupo se les mostraba el mismo objeto real e incluían un video donde se mostraban movimientos que involucraban su uso. Los resultados mostraron que las ayudas en el video donde se apreciaba la realización del movimiento con el uso del objeto eran fundamentales para tener mayores beneficios.

Se ha reportado que cuando se les brindan ayudas fonológicas en la nominación a los pacientes con afasia, existe un incremento en expresión del lenguaje después de un programa de tres horas diarias durante dos semanas (Menket et al, 2009). Del mismo modo, Best et al. (2013) implementaron un programa intensivo con ayudas fonológicas en pacientes con afasia, y midieron su efecto si lograban una generalización en otro tipo de palabras. El programa consistía en mostrar objetos y brindar ayudas fonológicas, en sesiones diarias por ocho semanas. Los resultados mostraron una mejoría significativa e incluso mostrando generalización en palabras no tratadas.

Por último, Adelt, Hanne y Stadie (2016), realizaron una intervención en pacientes con trastornos afásicos, teniendo como principal objetivo evaluar si el entrenamiento con fluidez verbal apoyaba y mejoraba la comprensión y de manera inversa si el entrenamiento en comprensión mejoraba la fluidez de los pacientes. En dicho estudio un grupo de pacientes con afasia era entrenado en tareas de nominación mientras que en otro se realizaba la intervención en tareas de comprensión las cuales era darles una instrucción, separar en cantidad de órdenes dadas, repetirlas y realizarlas. Con dichos entrenamientos los pacientes mostraron mejoría en los procesos entrenados, no obstante, con respecto al entrenamiento en comprensión, los pacientes también mostraron una mejoría en su fluidez, reduciendo sus parafasias y anomias.

En el presente estudio se propone un plan de intervención corto que mejore habilidades de nominación en un paciente con ATM mediante la utilización de una serie de claves (dibujos, letras, fonemas, etc.) que permitan al paciente recuperar la información (Cuetos, 2001). Por lo tanto, la rehabilitación tuvo el objetivo de mejorar el lenguaje expresivo y comprensivo del paciente para una mayor autonomía.

\section{Descripción del caso}


Paciente masculino de 75 años de edad, quien sufrió un EVC isquémico, en la artería cerebral media en su rama anterior en el 2016 y por consecuencia presentó un trastorno afásico.

Se realizó una evaluación neuropsicológica en las instalaciones del Laboratorio de Neurometría de la FES Iztacala, utilizando el Mini Examen del Estado Mental (MMSE) y el Programa Integral de Exploración Neuropsicológica (Heres \& Casanova, 1994) para el diagnóstico de afasia. Finalmente, se utilizó el Test de Token (Renzi \& Faglioni, 1978) y categorías semánticas para el pretest y postest.

Los resultados obtenidos de la valoración fueron entregados al paciente mediante un reporte en el cual se mencionaba el diagnóstico de afasia transcortical motora, considerando los parámetros de González y González (2012) e incluyendo los siguientes síntomas:

- Lenguaje no fluido

- Ecolalia

- Parafasias fonológicas

- Presencia de frases cortas

- Discurso disminuido

- Anomias

- Repetición conservada

- Adecuada lectura

- Escritura afectada con perseveraciones

- Hemiparesia derecha

\section{Programa de Rehabilitación}

\section{Sesiones}

Se realizaron 19 sesiones, una vez por semana, cada sesión con una duración de una hora aproximadamente.

\section{Material}

Se utilizaron imágenes de diferentes objetos, productos, acciones y expresiones faciales. Estas imágenes fueron seleccionadas con el fin de ser objetos de uso cotidiano que ayuden a futuras implementaciones de trabajos terapéuticos y aumentar su repertorio de nominación. El programa se dividió en dos fases, una enfocada en el lenguaje expresivo y la segunda en el lenguaje comprensivo.

\section{Fase 1}

Actividad de nominación: presentación de imágenes, con facilitadores semánticos y fonológicos.

En la primera sección el programa de rehabilitación presenta las siguientes características generales, las cuales se emplean en las sesiones con el fin de mejorar la nominación de palabras.
Procedimiento nominación

1. Se seleccionarán imágenes de un campo semántico, para trabajar en cada sesión.

2. El paciente se colocará de manera cómoda frente al terapeuta, quien le mostrará imágenes de las cuales tendrá que decir el nombre del objeto.

3. Si logra nominar el objeto, se continuará con la presentación de otra imagen.

4. En caso de que no logré nominar la palabra, se le dará una ayuda semántica para conseguir la nominación. En caso de lograr la nominación se le pedirá al paciente que repita la palabra por tres ocasiones. En caso de que no, se continuará con las ayudas.

5. En caso de que no logré nominar la imagen, se le darán en primer lugar una clave fonológica sobre la palabra a nominar, en caso de que no lo logré se le darán dos claves fonológicas. Si logra nominar en alguna de las dos ayudas fonológicas, se le pedirá que repita el nombre de la palabra tres veces. En caso de que no lo logré se le dirá el nombre de la palabra y que él la repita por tres ocasiones más.

6. Todas las sesiones contarán con un registro para revisar sus nominaciones y avances durante las sesiones.

7. Se agregará una categoría semántica más, cada vez que logré el $80 \%$ mínimo de la nominación de la categoría presentada.

\section{Fase 2}

Actividad de comprensión: presentación de órdenes, identificación de cantidad de órdenes y realización de órdenes.

Procedimiento de comprensión.

1. En primer lugar, se seleccionan los materiales necesarios a ocupar y se redactan las órdenes a trabajar, con una dificultad gradual y con una redacción sencilla, comenzando con una orden y aumentando hasta tres órdenes en un mismo enunciado.

2. Se le asignan 6 fichas rojas.

3. Se le menciona la orden u órdenes a realizar.

4. El paciente debe repetir la orden mencionada.

5. El paciente debe darle a terapeuta el número de fichas que corresponda al número de órdenes brindadas. 
6. Se le cuestiona sobre las órdenes brindadas, ¿quién tiene que realizarlas? ¿qué tiene que realizar?

7. El paciente debe realizar la orden mencionada.

8. Durante todo el procedimiento se le debe corregir al paciente, incitando a que el mismo detecte los errores y corregirlos con él.

\section{Resultados}

Pretest

Con respecto a la puntuación obtenida en la línea base de la nominación de palabras que se emplearán durante el programa, se presentan en la siguiente tabla 1.

\begin{tabular}{|c|c|c|c|c|}
\hline $\begin{array}{l}\text { 1. Productos de } \\
\text { supermercado }\end{array}$ & $11 / 25$ & 6 & 3 & $44 \%$ \\
\hline 2. Frutas & $8 / 19$ & 2 & 3 & $42 \%$ \\
\hline 3. Carnes & $5 / 6$ & 0 & 0 & $83 \%$ \\
\hline $\begin{array}{l}\text { 4. Productos de } \\
\text { aseo personal }\end{array}$ & $4 / 13$ & 1 & 1 & $30 \%$ \\
\hline $\begin{array}{l}\text { 5. Productos de } \\
\text { limpieza }\end{array}$ & $6 / 14$ & 3 & 2 & $42 \%$ \\
\hline 6. Animales & $12 / 18$ & 1 & 2 & $66 \%$ \\
\hline $\begin{array}{l}\text { 7. Objetos del } \\
\text { hogar }\end{array}$ & $15 / 18$ & 0 & 2 & $83 \%$ \\
\hline 8. Cubiertos & $7 / 11$ & 0 & 0 & $63 \%$ \\
\hline 9. Verduras & $7 / 10$ & 1 & 2 & $70 \%$ \\
\hline 10. Transporte & $5 / 8$ & 1 & 2 & $62 \%$ \\
\hline 11. Acciones & $7 / 12$ & 2 & 1 & $58 \%$ \\
\hline 12. Herramientas & $3 / 9$ & 2 & 2 & $33 \%$ \\
\hline $\begin{array}{l}\text { 13. Señales de } \\
\text { transito }\end{array}$ & $5 / 9$ & 0 & 1 & $55 \%$ \\
\hline $\begin{array}{l}\text { 14. Partes del } \\
\text { cuerpo }\end{array}$ & $8 / 20$ & 1 & 3 & $40 \%$ \\
\hline 15. Medicamentos & $1 / 7$ & 2 & 1 & $14 \%$ \\
\hline 16. Dinero & $10 / 13$ & 2 & 0 & $76 \%$ \\
\hline 17. Vestimenta & $11 / 14$ & 1 & 1 & $78 \%$ \\
\hline 18. Emociones & $4 / 9$ & 1 & 2 & $44 \%$ \\
\hline
\end{tabular}

Tabla 1. Número de palabras nominadas correctamente en cada una de las categorías semánticas aplicadas al paciente.

\section{Postest}

Con respecto a los resultados obtenidos por el paciente en las nominaciones de las imágenes, el señor logró nominar todas las palabras utilizadas, eso incluye con ayudas fonológicas, no obstante de manera libre se presentan en la mayoría de las categorías ligeras mejorías con respecto a la nominación línea base (Tabla 2).

\begin{tabular}{llllll}
\hline Categoría & Nomia & Un & Dos & $\%$ Pos & $\%$ \\
Semántica & $\begin{array}{l}\text {-ción } \\
\text { fone } \\
\text { libre }\end{array}$ & $\begin{array}{l}\text { fone } \\
\text {-ma }\end{array}$ & -mas & & $\begin{array}{l}\text { P } \\
\text { re }\end{array}$ \\
\hline
\end{tabular}

\begin{tabular}{|c|c|c|c|c|c|}
\hline $\begin{array}{l}\text { 1.Productos } \\
\text { de supermer- } \\
\text { cado }\end{array}$ & $19 / 25$ & 6 & 0 & $76 \%$ & $\begin{array}{l}4 \\
4 \\
\%\end{array}$ \\
\hline 2.Frutas & $6 / 19$ & 13 & 0 & $32 \%$ & $\begin{array}{l}4 \\
2 \\
\%\end{array}$ \\
\hline 3. Carnes & $5 / 6$ & 1 & 0 & $83 \%$ & $\begin{array}{l}8 \\
3 \\
\%\end{array}$ \\
\hline $\begin{array}{l}\text { 4.Productos } \\
\text { de aseo } \\
\text { personal }\end{array}$ & $8 / 13$ & 4 & 1 & $62 \%$ & $\begin{array}{l}3 \\
0 \\
\%\end{array}$ \\
\hline $\begin{array}{l}\text { 5.Productos } \\
\text { de limpieza }\end{array}$ & $9 / 14$ & 4 & 2 & $64 \%$ & $\begin{array}{l}4 \\
2 \\
\%\end{array}$ \\
\hline 6.Animales & $12 / 18$ & 4 & 2 & $66 \%$ & $\begin{array}{l}6 \\
6 \\
\%\end{array}$ \\
\hline $\begin{array}{l}\text { 7.Objetos del } \\
\text { hogar }\end{array}$ & $15 / 18$ & 2 & 1 & $83 \%$ & $\begin{array}{l}8 \\
3 \\
\%\end{array}$ \\
\hline 8.Cubiertos & $8 / 11$ & 2 & 1 & $73 \%$ & $\begin{array}{l}6 \\
3 \\
\%\end{array}$ \\
\hline 9.Verduras & $4 / 10$ & 4 & 2 & $40 \%$ & $\begin{array}{l}7 \\
0 \\
\%\end{array}$ \\
\hline $\begin{array}{l}\text { 10.Transport } \\
\text { e }\end{array}$ & $5 / 8$ & 2 & 1 & $62 \%$ & $\begin{array}{l}6 \\
2 \\
\%\end{array}$ \\
\hline 11.Acciones & $7 / 12$ & 4 & 1 & $58 \%$ & $\begin{array}{l}5 \\
8 \\
\%\end{array}$ \\
\hline $\begin{array}{l}\text { 12.Herrami- } \\
\text { entas }\end{array}$ & $3 / 9$ & 5 & 1 & $33 \%$ & $\begin{array}{l}3 \\
3 \\
\%\end{array}$ \\
\hline $\begin{array}{l}\text { 13.Señales } \\
\text { de transito }\end{array}$ & $6 / 9$ & 2 & 1 & $55 \%$ & $\begin{array}{l}5 \\
5 \\
\%\end{array}$ \\
\hline $\begin{array}{l}\text { 14.Partes del } \\
\text { cuerpo }\end{array}$ & $11 / 20$ & 6 & 2 & $40 \%$ & $\begin{array}{l}4 \\
0 \\
\%\end{array}$ \\
\hline $\begin{array}{l}\text { 15.Medica- } \\
\text { mentos }\end{array}$ & $1 / 7$ & 6 & 0 & $14 \%$ & $\begin{array}{l}1 \\
4 \\
\%\end{array}$ \\
\hline 16. Dinero & $13 / 13$ & 0 & 0 & $100 \%$ & $\begin{array}{l}7 \\
6 \\
\%\end{array}$ \\
\hline $\begin{array}{l}\text { 17.Vesti- } \\
\text { menta }\end{array}$ & $11 / 14$ & 3 & 0 & $78 \%$ & $78 \%$ \\
\hline $\begin{array}{l}\text { 18.Emo- } \\
\text { ciones }\end{array}$ & $7 / 11$ & 4 & 0 & $63 \%$ & $44 \%$ \\
\hline
\end{tabular}

Tabla 2. Resultados obtenidos por el paciente en la nominación de imágenes utilizadas durante el tratamiento. 
Por último, se presenta la gráfica que compara los porcentajes de respuestas correctas en la evaluación pre y pos tratamiento en cada una de las categorías. Se puede observar de manera general que el paciente presenta una ligera mejor nominación en las palabras empleadas, con excepción de las categorías de frutas y verduras, ambas utilizadas durante el tratamiento (Gráfico 1).

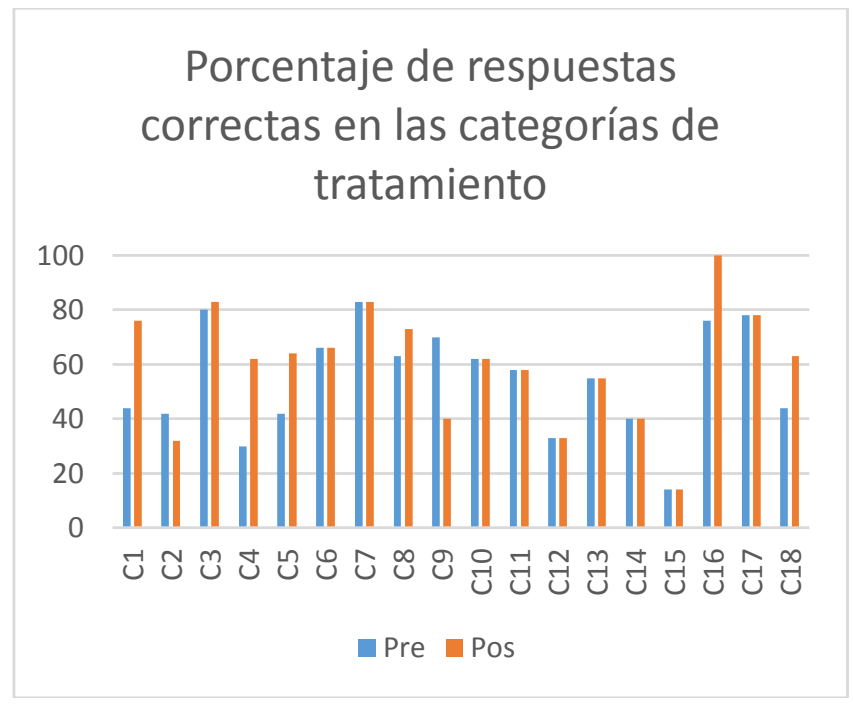

Gráfica 1. Porcentaje de respuestas correctas obtenidos por el paciente en la evaluación pre y post tratamiento. La lista de categorías se muestra en la Tabla 6.

\section{Token test}

La siguiente tabla, muestra los resultados obtenidos pre y pos tratamiento en la prueba Token, la cual mide aspectos de comprensión mostrando una mejora en su ejecución, obteniendo el mismo rango de afectación previa al tratamiento (Tabla 3).

\begin{tabular}{llll}
\hline & $\begin{array}{l}\text { Puntuación } \\
\text { Pretest }\end{array}$ & $\begin{array}{l}\text { Puntuación } \\
\text { Postest }\end{array}$ & $\begin{array}{l}\text { Grado de } \\
\text { afectación }\end{array}$ \\
\hline Paciente & 16 & 16.5 & Severo \\
\hline
\end{tabular}

Tabla 3. Puntuaciones obtenidas por el paciente en la prueba Token Test, ambas puntuaciones se encontraron dentro del rango de afectación severa.

\section{Discusión}

Los datos obtenidos con respecto a la ejecución en la nominación de imágenes, el área de la comprensión y en su atención sostenida del paciente mostró ligeras mejorías en cada uno de estos procesos. Por lo cual, a continuación se discutirán aspectos de los efectos de los tratamientos, los elementos de ayuda para el tratamiento de las afasias, el uso de estrategias para la comprensión, aspectos de la generalización de los resultados en el paciente y los objetivos alcanzados.

Con respecto a la técnica de rehabilitación implementada, presentación de imágenes que ayuden a la nominación de objetos, como los facilitadores fonológicos, han sido un recurso importante en la mejora de dicha actividad. Best et al. (2012) menciona que los tratamientos con la implementación de imágenes y ayudas fonológicas, mejora el rendimiento de pacientes afásicos, el presente estudio obtuvo resultados similares.

Con respecto a los facilitadores para la nominación, el paciente de este tratamiento mostró una mejor ejecución y recuperación del nombre con ayudas fonológicas, no obstante este paciente mostró un efecto interesante en su ejecución, la cual se presentó en las últimas dos sesiones, mostrando una mejor ejecución con ayudas semánticas aunque no logró nominar todas las palabras, condición que no había mostrado a lo largo de las sesiones previas, esta observación cualitativa podría explicarse a que el acceso a la nominación de imágenes por medio de recursos semánticos requiere mayor esfuerzo que las que son con ayudas fonológicas. Esta hipótesis concuerda con lo mencionado por Cuetos (2001), en el cual refiere que los tratamientos con ayudas fonológicos generan mejorías significativas que pacientes que se les brinda ayudas semánticas.

Con respecto a los objetivos general, se logró una ligera mejoraría en el lenguaje expresivo del paciente, no obstante, este cambio no fue significativo en pruebas estandarizadas. Sin embargo, logró mejorar la nominación y ligeramente su comprensión, que se vio reflejado la autonomía de actividades de la vida diaria.

Ahora bien, un proceso de rehabilitación no sólo puede incluir el trabajo en el proceso alterado, sino en la mejora de la calidad de vida, autonomía y funcionalidad del paciente, por lo que algunos autores mencionan que los pacientes afásicos presentan mejorías si se implementan actividad de integración social, en algunos casos, grupos de ayuda generen empatía e interés para el paciente en la vida cotidiana (Galletta y Barrett, 2014; Worrall et al. 2016).

\section{Conclusión}

El paciente de 75 años de edad presentó ligeras mejorías en áreas de nominación y comprensión, aun así, el paciente se ha beneficiado de técnicas de presentación de imágenes y facilitadores fonológicos para recuperar de 
manera exitosa un mayor número de palabras, que le podrá ser útiles en su vida cotidiana.

El uso de recursos como imágenes, ayudas fonológicas, y el seguimiento preciso y claro de órdenes orales son un adecuado recurso para mejorar dichos procesos, afectados por una lesión cerebrovascular que interfiere en el lenguaje.

\section{Referencias}

[1] Adelt, A., Hanne, S. \& Stadie, N., (2016). Treatment Of sentences comprehension and production in aphasia: is there cross-modal generasation?. Neuropsychological Rehabilitation. Acepted: 6 july 2016.

[2] Basso, A., Forbes, M., \& Boller, F. (2013). Rehabilitation of aphasia ELSEVIER,325- 334.

[3] Best, W., Greenwood, A., Grassly, J., Herbert, R., Hickin, J. \& Howard, D., 2013. Aphasia rehabilitation: does generalisation from anomia therapy occur and is it predictable? A Case series study. Cortex. 4: 49. 2345-2357.

[4] Bruna, O., Roig, T., Puyuelo, M., Junqué, C. \& Ruano, A., (2011) Rehabilitación Neuropsicológica. Intervención y práctica Clínica. Elservier. Masson. España.

[5] Chen, W., Ye., Q., Ji, X., Zhang, S., Yang, X., Zhou, Q., Cong, F., Chen, W., Zhang, X., Zhang, B., Xia, Y., Yuan, T., \& Shan C., (2015) Mirror neuron system based therapy for aphasia rehabilitation. 30:6.

[6] Cuetos, V., F. (2001). Evaluación y Rehabilitación de las Afasias. Editorial Panamericana. Madrid.

[7] Diéguez-Vide, F., \& Peña-Casanova, J. (2012). Cerebro y lenguaje. Sintomatología neurolingüística. Madrid: Médica Panamericana.

[8] Galletta, E., E., \& Barrett, M., A., (2014). Impairment and functional Intervention for Aphasia: Having it All. Psysical Medical Rehabilitation Rep. 2:114-120

[9] Galindo, A., M., G., Pelayo, G., H. \& Quintanar, R., L. (2014). Rehabilitación neuropsicológica en un caso de afasia motora aferente. Pensamiento Psicológico. 12:2. 97-112.

[10] Gonzáles, L., P. \& Gónzáles, O., B. (2013). Afasia De la teoría a la práctica. PANAMERICANA

[11] Heres, P. \& Peña, C., J. (1982). Ejercicios para la Rehabilitación de la Afasia de Wernicke. Revista logopedagógica. 1:3, (167-179).

[12] Lozano, P., G., \& Ortuño, B., G. (2011). Afasia. De la teoría a la práctica. México: Panamericana.

[13] Menket, R., Meinzer., M., Kugel, H., Deppe., M., Baumgärtner., A., Schiffbauer, H., Thomas, M., Kramer, K., Lohmann., H., Flöel, A. \& Knecht, S. (2009). Imaging short-and long-term training success in chronic aphasia. BMC Medical Education. 10:118

[14] Rodríguez, V., F., Solovieva, Y., Bonilla, S., M., Pelayo, G., J. \& Quintanar R., L., (2011). Rehabilitación neuropsicológica en un caso de afasia semántica. Revista neuropsicológica latinoamaricana. 3:2, 39-49.

[15] De Renzi, E., \& Faglioni, P. (1978). Normative data and screening power of a shortened version of the Token Test. Cortex, 14(1), 41-49.

[16] Worrall, L., Ryan, B., Hudson, K., Kneebone, I., Simmons-Mackie, N., Asaduzzaman, K., Hoffman,., T., Power, E., Togher, T. \& Rose, M., (2016). Reducing the psychosocial impact of aphasia on mood and quality of life in people with apahasia and impact of caregiving in family members through the aphasia action success knowledge (Aphasia Ask) program: study protocol for randomized controlled trial. National Heatlth and Medical Research Council for Clinical Research 17: 153. 